\title{
Leisure Reading Preferences of Bilingual Female Students in Singapore
}

\author{
Shaheen Majid \\ Nanyang Technological University \\ asmajid@ntu.edu.sg \\ Hazel Kai Jie Ng \\ Raffles Girls School \\ hazel.ng99@student.rgs.sg \\ Su Ying \\ Raffles Girls School \\ ying.su99@student.rgs.sg
}

\begin{abstract}
Background. Leisure reading is important for personal growth, enjoyment and relaxation.

Objective. The study investigates the influence of bilingualism on the leisure reading habits and preferences of female teenage students in Singapore.

Method. An online questionnaire was used to collect data and 464 students from two secondary schools that participated in this study.

Results. It was found that irrespective of ethnic group, 93\% of the students speak English at home, and also read leisure books in this language. For both English and mother tongue languages, the most favourite genres are fantasy, adventure, and romance, whereas the least preferred genres are sports, arts and craft, and biography. Students read English language books basically for enjoyment and relaxation, and mother tongue language books for study-related purposes.

Contributions. The limited interest in mother tongue languages could be a matter of concern for education planners, curriculum designers, and authors of children's literature. Appropriate measures are needed to encourage bilingual students to also read in their mother tongue language.
\end{abstract}

\section{INTRODUCTION}

Leisure reading plays a vital role in personality development and cognitive growth of children. It strengthens the thinking process and exposes readers to different perspectives and diverse viewpoints. Sustained reading can also improve students' reading comprehension, vocabulary, grammar, and appreciation for different writing styles. It can have a significant impact on their reading speed and fluency, overall verbal ability, and improved academic achievements (Lee, 2014; Majid \& Tan, 2007). Leisure reading, reading out of one's own accord, allows students to relax, learn, and reduce their study-related stress (McKool, 2007). In addition, it can expose students to different cultures, their unique characteristics, traditions and values, hence developing an appreciation, tolerance, respect and a positive attitude 
towards other people. Leisure reading can also improve general knowledge and develop an understanding of the contemporary issues.

Singapore is a multi-ethnic and multi-racial society, comprising mainly Chinese, Malays and Indians. English is the lingua franca of the country, serving as the common language that binds the different ethnic groups together (Mallozzi \& Malloy, 2007). A unique feature of the Singapore education system is its emphasis on a bilingual education policy (Wong, 2007). English language is the medium of instruction in all public schools and used for academic and extra-curricular activities. In addition to studying English as first language, students are required to study their mother tongue language as a second language (MOE, 2016). The bilingual education policy is likely to affect students' reading habits as they would acquire some level of competency in more than one language. It will be, therefore, interesting to study leisure reading preferences of bilingual students in Singapore.

The purpose of this study was to investigate the impact of bilingualism on the leisure reading habits of students in Singapore. By establishing a relationship between bilingualism and students' leisure reading habits, education planners and curriculum developers will be in a better position to effectively cater to the needs of students. In addition, the findings of this study will also be useful to teachers, school management, school librarians, and publishers of children's and young adults' literature in understanding the reading preferences of bilingual teenage students in Singapore.

\section{LITERATURE REVIEW}

A sizeable amount of literature is available on the different aspects of leisure reading by various reader groups, particularly by children and young adults. Many benefits are associated with leisure reading. In addition to relaxation, it can improve language skills of students (Majid \& Tan, 2007). Active reading can stimulate thinking and the reasoning process of students, thus enhancing their cognitive abilities (Hughes-Hassell \& Lutz, 2006). Reading avidness is also considered as one of the predictors of academic achievements (Mansor, Rasul, Rauf \& Koh, 2013). An international study, investigating reading competency in 35 countries, revealed that children reading for fun are more likely to achieve higher reading literacy scores (Ogle, Sen \& Phalke 2003). Another international study involving 13 countries also found that enjoyment of reading was a strong predictor in reading achievement (Lee, 2014). However, in many situations, students' main motivation for reading is to improve their academic performance. Majid and Tan (2007), based on their study of 440 upper primary students in Singapore, reported that the students were reading basically for academic reasons and to obtain better grades in examinations. An international survey on reading motivations showed that one-half of the surveyed British students were reading for relaxation, while a majority of the students from 12 developing countries were reading books for passing examinations (Books Aid International, 2003).

Studies on reading habits of students have shown that they like reading books on diverse topics and their reading preferences are changing. In Australia, students preferred reading action adventure, science fiction and fantasy (Woolcott Research, 2001). A study on the reading preferences of children in North Carolina revealed that girls were mostly reading books about arts and craft, health, fashion and beauty, whereas boys preferred reading books about sports, transportation and military topics (Sturm, 2003). A survey of 8,152 students from 98 schools in the UK revealed that adventure, humour, and horror were the most preferred genres (Clark \& Foster, 2005). In Singapore, girls preferred reading books on adventure, mysteries and comedy as well as books on fairy tales and relationships. On the 
other hand, boys preferred reading books on adventure, comedy and mysteries. Horror and science fiction books were equally popular among both genders (Majid \& Tan, 2007). Grant (2012) found that more female students preferred reading realistic fiction than male students.

Reading is a social activity and can be influenced by other people in the society. Mansor, Rasul, Rauf and Koh (2013) claimed that the reading ability of children is greatly influenced by parents. They also found that peers play an important role in shaping the reading interest and preferences of teenage students. Morton (2009) reported that family members can help develop a positive reading attitude among academically struggling students. Johnson (2016) found that reading to children can mould their reading habits. It was also revealed that, in addition to parents, teachers, cousins and friends can influence the reading choices of children. It was concluded that parents' involvement and encouragement are necessary to develop children's reading interest, as children are now constantly surrounded by technology. Grant (2012) also reported a significant relationship between parents' knowledge of children literature and children's reading scores. A study by Ko and Chan (2009) revealed that although Chinese parents consider their children's early literacy skills important, they rarely get involved in their reading activities. It was also found that the number of children's books at home is an important predictor of children's reading attainment scores.

In spite of the many benefits associated with reading, several studies suggest a decline in the reading habits of children and teenagers. The major reason for this decline is access to a wide array of leisure activities. Now there is an intense competition between books and innovative, attractive and engaging gadgets for capturing children's attention (Majid \& Tan, 2007). Ots (2006) explored the reading habits of students in Estonia and found that they were more interested in Web surfing and computer games than in reading books. Clark and Foster (2005) found that secondary school students enjoy reading much less than primary students. A study involving 1,174 middle school students in the United States noted that students were not interested in reading, thus spending very little time on various reading activities (Greenberg \& Frederick, 2006). Another study involving 2,200 children, aged between 7 and 16 years, revealed a considerable decline in book reading with increasing age (Haslett, 2002). Bokhorst-Heng and Pereira (2008) examined the reading behaviour of secondary students in Singapore and found a declining reading attitude among both genders. McKenna, Conradi, Lawrence, Jang and Meyer (2012) investigated the reading attitude of 4,491 middle school students in 23 states of the USA. Their study showed a gradual worsening of reading attitude of students from $6^{\text {th }}$ to $8^{\text {th }}$ grade.

Singapore puts a lot of emphasis on developing reading habits among different civic groups, including children and young adults. The Singapore government is making concerted efforts to prepare a new breed of students who are life-long learners. To achieve this objective, a network of public libraries is offering a variety of programmes to inculcate and promote reading habits among children (Majid \& Tan, 2007). Several initiatives have been launched to promote reading, such as KidsREAD clubs where volunteers, mostly university and college students, help children overcome their reading problems (Curdt-Christiansen, 2009). In June 2016, the National Library Board (NLB) launched a 5-year campaign called "National Reading Movement" in Singapore to encourage all citizens to read more, read widely and read together (NLB, 2016a). An area of focus of the National Reading Movement is to promote reading in mother tongue languages (NLB, 2016b). The first National Reading Day was celebrated in Singapore on July 30, 2016. 
In spite of Singapore's bilingual education policy and NLB initiatives to promote reading in mother tongue languages, limited research has been carried out to investigate the reading habits of bilingual students. The main purpose of this study was to bridge this gap by investigating the reading preferences of bilingual teenage students in Singapore. It is expected that the findings of this study will be useful to education planners, curriculum designers, public and school libraries, and authors and publishers of children's and young adults' literature.

\section{METHOD}

An online questionnaire was used to collect data from Secondary- 1 to Secondary-4 students (13 to 16 years old) from two secondary girls' schools in Singapore. The students were informed about the survey through internal school email systems. The questionnaire collected data about demographics of the respondents, languages spoken at home, types of materials read, preferred format and language for leisure reading, frequency of reading books, motivations behind reading books in different languages, and favourite genres in English and mother tongue languages. In order to ensure that the collected data were only from bilingual students, responses from students studying only one language were disregarded. A total of 464 female students participated in this study. Among them, 13 and 14-year old students accounted for the majority of the respondents (35.6\% and 33.2\% respectively). The proportion of 15 years old students was $25.4 \%$, while only $5.8 \%$ were 16 years old.

\section{RESULTS AND DISCUSSION}

A vast majority of the respondents (396 or 85.3\%) reported Chinese as their mother tongue, followed by Tamil (28 or $6.1 \%$ ), and Malay ( 24 or $5.2 \%$ ). The mother tongue languages of the remaining 16 (3.4\%) students were Hindi, Korean, French and some other languages. The participating students were asked if they have taken the higher mother tongue language subject in their schools. More than $93 \%$ of the students reported taking this subject for improving their mother tongue language competency. Most of the remaining students did not take the higher mother tongue language subject because either it was not offered due to few interested students or non-availability of specific language teacher.

\section{Languages Spoken at Home}

The students were asked about the languages spoken at their homes. The purpose was to investigate if the students were able to practice different languages at home, including their mother tongue language. It was interesting to note that a big proportion (92.5\%) of the students spoke English at home (Table 1). Out of 396 Chinese students, only 256 (64.6\%) said that they spoke Chinese at home. The percentage of Tamil (Indian) and Malay students speaking their mother tongue languages at home were $82.1 \%$ and $91.7 \%$ respectively.

A further analysis of the number of languages spoken at home by ethnic groups yielded interesting results. It was found that $63 \%$ of the students were speaking at least two languages at home (Table 2). It was also noted that $37.1 \%$ of the students were monolingual, either speaking English or mother tongue language at home.

\section{Reading Habits of the Students}

The students were asked that when they were a child, how much reading was encouraged by their parents, teachers, and others. A 5-point Likert scale was used to gather responses, where 
Table 1. Language(s) spoken at home (multiple response)

\begin{tabular}{lccc}
\hline Language & N & Frequency & Percent \\
\hline English & 464 & 429 & 92.5 \\
Chinese & 396 & 256 & 64.6 \\
Tamil & 28 & 23 & 82.1 \\
Malay & 24 & 22 & 91.7 \\
Others & 16 & 16 & 100.0 \\
\hline
\end{tabular}

Table 2. Number of languages spoken at home by ethnic group

\begin{tabular}{lcrrr}
\hline & & \multicolumn{3}{c}{ No. of languages spoken } \\
\cline { 3 - 5 } Language & $\mathbf{N}$ & $\mathbf{1}$ & \multicolumn{1}{c}{$\mathbf{2}$} \\
\hline Chinese & 396 & $148(37.4 \%)$ & $233(58.8 \%)$ & $15(3.8 \%)$ \\
Tamil & 28 & $11(39.3 \%)$ & $17(60.7 \%)$ & $0(0.0 \%)$ \\
Malay & 24 & $7(29.2 \%)$ & $16(66.7 \%)$ & $1(4.2 \%)$ \\
Others & 16 & $6(37.5 \%)$ & $8(50.0 \%)$ & $2(12.5 \%)$ \\
\hline Total & 464 & $172(37.1 \%)$ & $274(59.1 \%)$ & $18(3.9 \%)$ \\
\hline
\end{tabular}

Table 3. Time spent on leisure reading per week

\begin{tabular}{lcc}
\hline Hours per week & Frequency & Percent \\
\hline Less than 7 hours & 233 & 50.2 \\
$7-10$ hours & 103 & 22.2 \\
11 - 15 hours & 63 & 13.6 \\
More than 15 hours & 34 & 7.3 \\
I do not read books at all & 31 & 6.7 \\
\hline
\end{tabular}

Table 4. Types of materials read $(\mathrm{N}=464)$

\begin{tabular}{lcc}
\hline Types of materials & Mean (1 5) & SD \\
\hline Fiction books & 4.67 & .781 \\
Newspapers & 2.88 & 1.261 \\
Non-fiction books & 2.72 & 1.216 \\
Magazines & 2.38 & 1.255 \\
Scholarly Articles & 2.14 & 1.089 \\
\hline
\end{tabular}

1 was "least encouraged" and 5 was "highly encouraged". It was found that the students got strong encouragement (mean: 4.28, SD: 0.895) for reading during their childhood. Several previous studies have also shown that encouragement from parents, siblings, peers and teachers can help develop reading habits among children (Grant, 2012; Johnson, 2016; Mansor, Rasul, Rauf \& Koh, 2013).

Furthermore, the students were asked how much time on average they spent reading books every week. Slightly over half of the students reported spending less than 7 hours per week reading books (Table 3). The percentage of students spending 7 to 10 hours on leisure reading was $22.2 \%$. However, it was worth noting that only $6.7 \%$ of the surveyed students were not reading books at all.

The students were also asked how frequently they read different types of materials. The purpose was to identify the types of materials popular among teenage female students. Five 


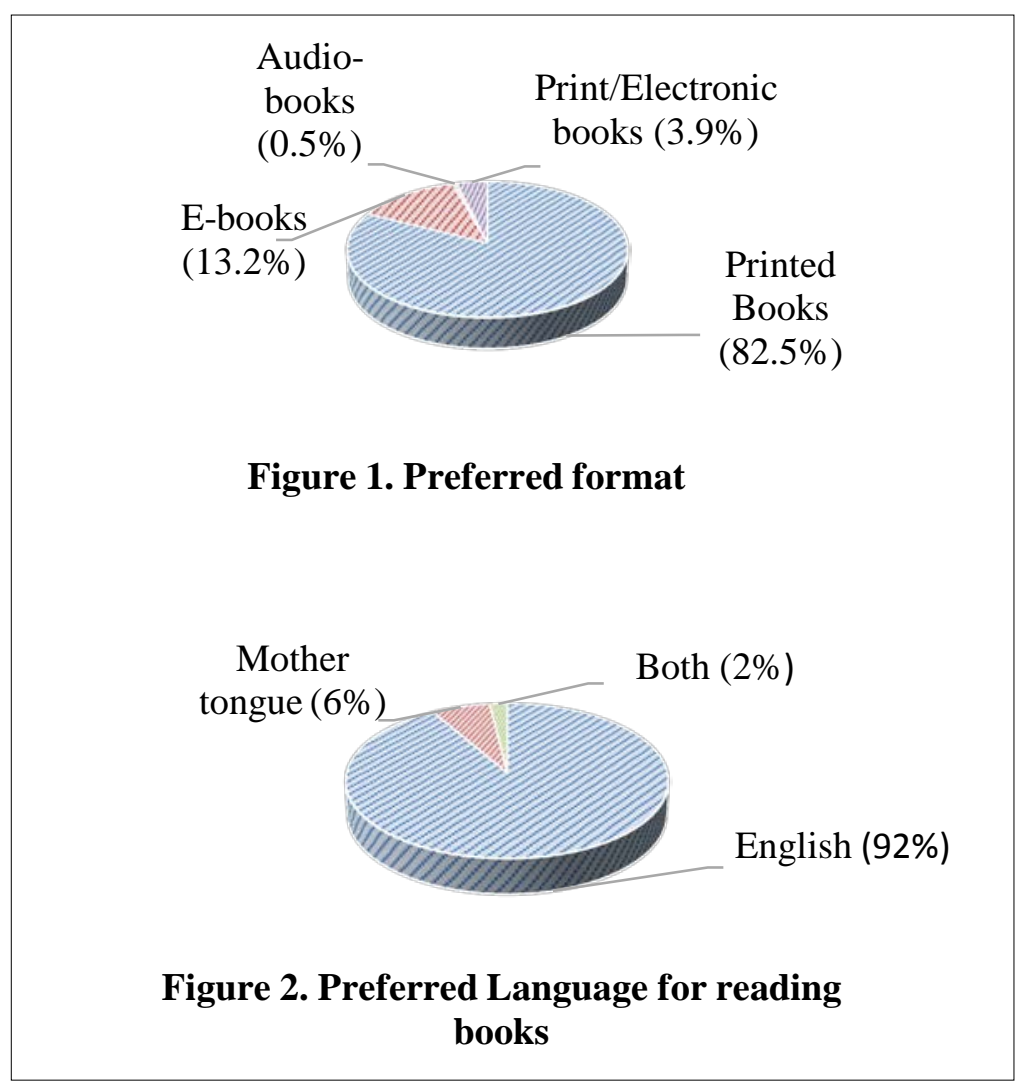

types of materials were listed in the questionnaire, that is, fiction, non-fiction, newspapers, magazines, and scholarly articles. A 5-point Likert scale, where 1 represented "never" and 5 "very often", was used to collect data. It was found that fiction books were the most popular among the teen female students with a mean score of 4.67 (Table 4). Comparatively, the mean scores for all other types of materials were low, within a range of 2.14 to 2.88 .

\section{Preferred Format for Reading Books}

The students were asked in what format they preferred to read leisure books. They were given four choices, that is, printed books, e-books, audio-books, and both printed and electronic books. An overwhelming majority (82.5\%) of the students showed their preference for traditional printed books (Figure 1). E-books were liked by only $13.2 \%$ of the students. Another 3.9\% of the students expressed equal preference for printed and electronic books. A study by Pešut and Živković (2016) also found that students still preferred reading traditional printed books over electronic books.

\section{Preferred Language for Reading Books}

It was found that most (92\%) of the students preferred reading books in English language (Figure 2). Only 6\% of the students were readings books in their mother tongue languages, while the remaining two percent were reading both in English and mother tongue languages. This finding is understandable as earlier $92.5 \%$ of the students (Table 1) reported speaking English at home, indicating their level of comfort with it. However, it was worth noting that although $63 \%$ of the students were speaking two or more languages at home, they preferred reading books in the English language. 
Table 5. Preferred genres of English language books ( $N=464)$

\begin{tabular}{clcc}
\hline S. No. & Genres & Mean (1 5) & SD \\
\hline 1 & Fantasy & 4.12 & 1.059 \\
2 & Adventure & 4.09 & .993 \\
3 & Romance & 3.49 & 1.260 \\
4 & Fan fiction & 3.35 & 1.457 \\
5 & Science fiction & 3.24 & 1.308 \\
6 & Poetry & 2.48 & 1.292 \\
7 & History & 2.36 & 1.246 \\
8 & Biography & 2.06 & 1.141 \\
9 & Arts and Craft & 2.06 & 1.165 \\
10 & Sports & 1.61 & .932 \\
\hline
\end{tabular}

Table 6. Preferred genres of mother tongue books $(\mathrm{N}=464)$

\begin{tabular}{clcc}
\hline S. No. & Genres & Mean (1 5) & SD \\
\hline 1 & Adventure & 2.80 & 1.526 \\
2 & Fantasy & 2.77 & 1.581 \\
3 & Romance & 2.39 & 1.473 \\
4 & Poetry & 1.96 & 1.241 \\
5 & Science fiction & 1.93 & 1.239 \\
6 & Fan fiction & 1.76 & 1.188 \\
7 & History & 1.75 & 1.159 \\
8 & Biography & 1.61 & 1.027 \\
9 & Arts and Craft & 1.56 & .899 \\
10 & Sports & 1.34 & .744 \\
\hline
\end{tabular}

\section{Preferred Genres for English Language Books}

Students were provided a list of ten possible genres and asked to indicate their preference on a 5 -point Likert scale, where 1 was "least preferred" and 5 "most preferred". As shown in Table 5, the most favoured genre was fantasy (mean: 4.12), closely followed by adventure (mean: 4.09). This finding concurs with a study by Woolcott Research (2001) where fantasy was also liked by Australian students. Similarly, several previous studies suggested that adventure was one of the favourite genres for leisure reading by students (Clark \& Foster, 2005; Majid \& Tan, 2007; Woolcott Research, 2001). The three least preferred genres were: sports (mean: 1.61), arts and craft (mean: 2.06), and biography (mean: 2.06).

\section{Preferred Genres for Mother Tongue Books}

The students were also asked to express their preference for books in mother tongue languages, using the same ten genres used for English language books. Table 6 reflects that the two most popular genres were adventure (mean: 2.80) and fantasy (mean: 2.77). Like for English language books, the three least preferred genres were sports (mean: 1.34), arts and craft (mean: 1.56), and biography (mean: 1.61). It was also worth noting that the mean scores for all genres in mother tongue languages were lower than 3.0, indicating their limited popularity among the students.

As can be seen in Figure 3, the three most popular genres (i.e. fantasy, adventure, and romance) and the three least preferred genres (i.e. biography, arts and craft, and sports) were 


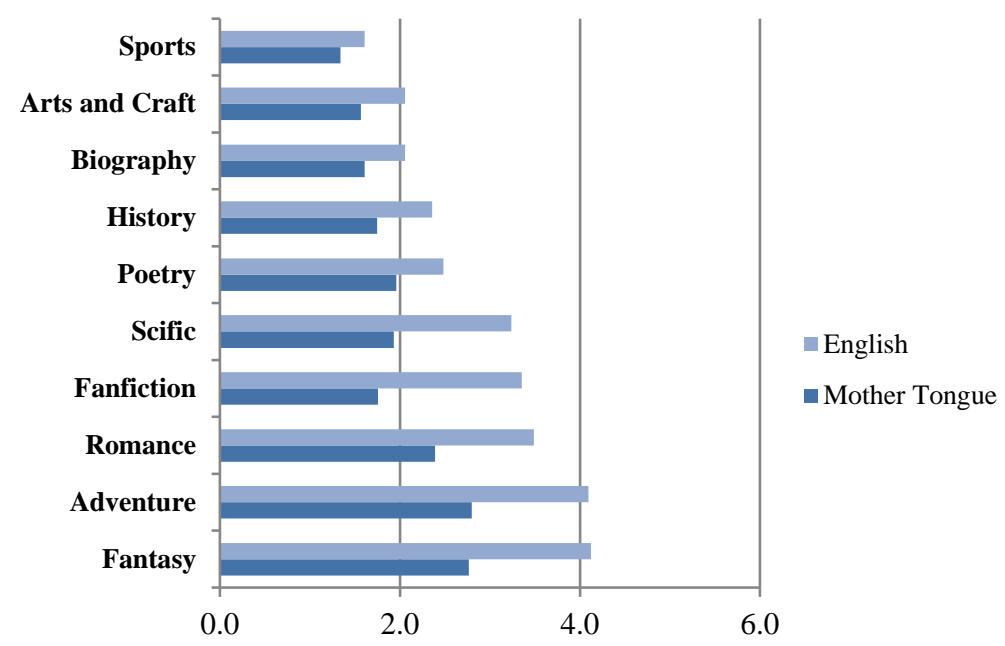

Figure 3. Preferred genres for English and mother tongue languages

the same for both English language and mother tongue languages. It should be noted that all genres of English language books obtained higher mean scores compared to books in mother tongue languages. A paired samples t-test confirmed this. For each genre, the difference in the preference value between English language and mother tongue languages was highly significant (for all pairs, $\mathrm{p}==<0.01$ ).

\section{Reasons for Reading Books in English Language}

The students were asked about the reasons for reading books in the English language. Nine possible reasons were listed in the questionnaire, with an open-ended option. As shown in Table 7, the two most important reasons for reading books in the English language were "genuine interest in reading" (mean: 4.64), and "relaxation" (mean: 4.59). These were followed by "friends' recommendations" (mean: 3.63) and "boredom" (3.34). This finding is in line with a survey in the UK where a majority of the students said that they read books for pleasure and relaxation (Books Aid International, 2003).

It was interesting to note that three study-related reasons, that is, "to improve linguistic skills", "requirement of project work", and "to obtain higher grades" were not the popular reasons for leisure reading. This finding is different from a previous study by Majid and Tan (2007) in Singapore where better academic performance was the major reason for leisure reading by upper primary students.

\section{Reasons for Reading Books in Mother Tongue Language}

A completely different picture emerged when the students were asked to provide possible reasons for reading books in their mother tongue languages. It was found that the four least important reasons for reading English language books became the most important reasons for reading books in mother tongue languages (Table 8). These reasons were: "to obtain higher grades” (mean 3.57), "to improve linguistic skills" (mean: 3.46), "requirement of project work” (3.24), and "parents’ advice” (mean 2.83). It appears that the students were basically reading literature in their mother tongue languages for study-related purposes as well as to satisfy their parents. 
Table 7. Reasons for reading books in the English language $(\mathrm{N}=464)$

\begin{tabular}{clcc}
\hline S. No. & Reasons & Mean (1 5) & SD \\
\hline 1 & Genuine interest in reading & 4.64 & .764 \\
2 & Relaxation & 4.59 & .850 \\
3 & Friends' recommendations & 3.63 & 1.192 \\
4 & Boredom & 3.34 & 1.473 \\
5 & To keep up with current knowledge & 3.02 & 1.326 \\
6 & To improve linguistic skills & 3.00 & 1.337 \\
7 & Requirement of project work & 2.46 & 1.202 \\
8 & To obtain higher grades & 2.40 & 1.274 \\
9 & Parents' advise & 1.69 & .999 \\
\hline
\end{tabular}

Table 8. Reasons for reading books in mother tongue language $(\mathrm{N}=464)$

\begin{tabular}{clcc}
\hline S. No. & Reasons & Mean (1 5) & SD \\
\hline 1 & To obtain higher grades & 3.57 & 1.459 \\
2 & To improve linguistic skills & 3.46 & 1.472 \\
3 & Requirement of project work & 3.24 & 1.556 \\
4 & Parents' advise & 2.83 & 1.560 \\
5 & Genuine interest in reading & 2.42 & 1.517 \\
6 & Relaxation & 2.20 & 1.449 \\
7 & Boredom & 2.10 & 1.367 \\
8 & To keep up with current knowledge & 1.95 & 1.177 \\
9 & Friends' recommendations & 1.90 & 1.178 \\
\hline
\end{tabular}

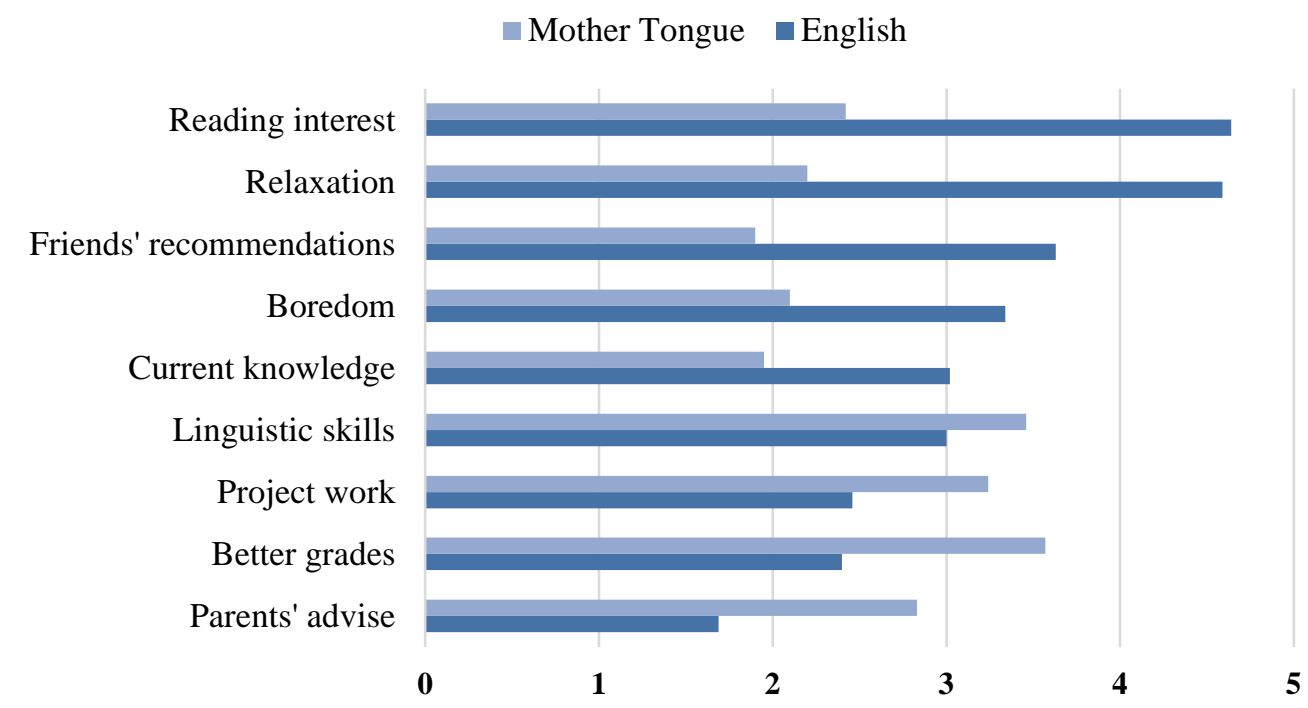

Figure 4. Reasons for reading in English and mother tongue languages 
Figure 4 shows that the reasons for reading literature in English language and in mother tongue languages were considerably different. The students were basically reading books in the English language for entertainment and relaxation, while they were reading books in mother tongue languages for better academic performance.

A paired samples t-test showed that for reading English language books, the reasons "genuine interest in reading”, "relaxation”, “friends' recommendations", "boredom”, and "to keep up with current knowledge” were significantly more important than reading books in mother tongue languages ( $\mathrm{p}=<0.01$ ). On the contrary, for reading books in mother tongue languages, the reasons "to improve linguistic skills", "requirement for project work", "to obtain higher grades”, and "parents' advise” were significantly more important than for reading English language books $(\mathrm{p}=<0.01)$.

\section{CONCLUSION}

The findings of this study suggest that motivations of bilingual students for leisure reading are considerably different for books in the English language and in their mother tongue languages. Books in the English language were read more frequently and basically for interest in reading and relaxation. Books in the mother tongue language were read less frequently and mainly for academic purposes. It was interesting to note that the language spoken at home had little impact on students' leisure reading preferences. It also indicates that current efforts to promote mother tongue languages among Singapore students have achieved a limited success. There is a need for curriculum planners and teachers to review the subject content and pedagogy used for teaching mother tongue languages to encourage students to also read books in their own mother tongue languages to stay connected with their culture and heritage.

Similarly, the National Library Board (NLB) needs to assess the effectiveness of its initiatives to promote mother tongue languages among children. It should also review the children's collections in its network of public libraries to determine their adequacy and appropriateness for bilingual children. Likewise, publishers of children and young adults' literature should produce materials which are suitable for bilingual children with limited language proficiency. Such materials need to be short, easy to read, and should only use a basic vocabulary to make leisure reading in mother tongue languages more enjoyable and less stressful.

\section{REFERENCES}

Bokhorst-Heng, W., \& Pereira, D. (2008). Non-at-risk adolescents’ attitudes towards reading in a Singapore secondary school. Journal of Research in Reading, 31(3), 285-301. https://doi.org/10.1111/j.1467-9817.2008.00369.x

Books Aid International (2003). Is reading a dying pastime? Retrieved June 10, 2016, from http://news.cision.com/pressreleases-uk/r/is-reading-a-dying-pastime-,c75495

Clark, C., \& Foster, A. (2005). Children's and young people's reading habits and references. National Literacy Trust. Retrieved from http://www.literacytrust.org.uk/assets/0000/0577/Reading_Connects_Survey_2005.pdf

Curdt-Christiansen, X.L. (2009). Love of reading: An evaluation of the KidsREAD programme in Singapore. International Journal of Learning, 16(9), 69-85.

Grant, A.K. (2012). Exploring the relationship between genre preferences and reading skills: Are boys really such poor readers? Dissertations Abstracts International: The Science \& Engineering, 73(4-B), 2543. 
Greenberg, D., Gilbert, A., Fredrick, L. (2006). Reading interest and behavior in middle school students in inner-city and rural settings. Reading Horizons Journal, 47(2), 159173.

Haslett, D. (2002) What's the story? The reading choices of young people in Ireland. Children's Books Ireland.

Hughes-Hassell, S., \& Lutz, C. (2006). What do you want to tell us about reading? A survey of the habits and attitudes of urban middle school students toward leisure reading. Young Adult Library Services, 4(2), 39-45.

Johnson, K. (2016). Parental perceptions of the influence of digital media and technology on children's reading habits at home. Dissertation Abstracts International: Humanities and Social Sciences, 76(7-A) (E).

Ko, H.W., \& Chan, Y.L. (2009). Family factors and primary students' reading attainment: A Chinese community perspective. Chinese Education \& Society, 42(3), 33-48. https://doi.org/10.2753/CED1061-1932420302

Lee, J. (2014). Universal factors of student achievement in high-performing eastern and western countries. Journal of Educational Psychology, 106(2), 364-374. https://doi.org/10.1037/a0035609

Majid, S., \& Tan, V. (2007). Understanding the reading habits of children in Singapore. Journal of Educational Media \& Library Sciences, 45 (2), 187-198

Mallozzi, C., \& Malloy, J.A. (2007). Second-language issues and multiculturalism. Reading Research Quarterly, 42(3), 430-436. https://doi.org/10.1598/RRQ.42.3.9.

Mansor, A., Rasul, M. Rauf, R., \& Koh, B. (2013). Developing and sustaining reading habit among teenagers. Asia-Pacific Education Researcher, 22(4), 357-365.

McKenna, M., Conradi, K., Lawrence, C., Jang, B.G., \& Meyer, J.P. (2012). Reading attitudes of middle school students: Results of a U.S. survey. Reading Research Quarterly, 47(3), 283-306. https://doi.org/10.1002/RRQ.021.

McKool, S.S. (2007). Factors that influence the decision to read: An investigation of fifth grade students' out-of-school reading habits. Reading Improvement, 44 (3), 111-131

MOE [Ministry of Education, Singapore]. (2016). Mother tongue language policy. Retrieved from https://www.moe.gov.sg/admissions/returning-singaporeans/singaporeansreturning-home/mother-tongue-policy

Morton, S. (2009). At risk, urban seventh and eighth grade summer school students' perspectives on their reading practices and preferences. Dissertation Abstracts International: Humanities and Social Sciences, 70(2-A), 516.

NLB [National Library Board]. (2016a). National reading movement: Building a nation of readers. Retrieved from http://www.nationalreadingmovement.sg/

NLB [National Library Board]. (2016b). Book clubs. Retrieved from http://www.nlb.gov.sg/readsingapore/book-clubs/

Ogle, L.T; Sen, A. \& Pahlke, E. (2003). International comparisons in fourth-grade reading literacy: Findings from the Progress in International Reading Literacy Study (PIRLS) of 2001. Retrieved from http://nces.ed.gov/pubs2003/2003073.pdf

Ots, L. (2006). The cultural and reading habits of students, parents and teachers. International Journal of Learning, 13(1), 155-162.

Pešut, D., \& Živković, D. (2016). Students' academic reading format preferences in Croatia. New Library World, 117(5/6), 392-406.

Sturm, B.W. (2003). The information and reading preferences of North Carolina children, School Library Media Research, vol. 6, 1-29. Retrieved from 
-ibres volume 27, issue 1, pages 1-12 (2017)

http://www.ala.org/aasl/sites/ala.org.aasl/files/content/aaslpubsandjournals/slr/vol6/SL MR_InfoReadingPreferences_V6.pdf

Wong, R. (2007). Second-language issues and multiculturalism. Reading Research Quarterly, 42(3), 430-436. https://doi.org/10.1598/RRQ.42.3.9

Woolcott Research. (2001). Young Australian reading: From keen to reluctant readers.

Retrieved from http://www2.slv.vic.gov.au/pdfs/aboutus/publications/yar_report.pdf 